УДК 666.972

\title{
КОМПЛЕКСНОЕ ИССЛЕДОВАНИЕ МОДИФИЦИРОВАННОГО БЕТОНА НА ОСНОВЕ АКТИВИРОВАННОГО МИКРОКРЕМНЕЗЕМА СОВМЕСТНО С МИКРОАРМИРУЩИМ ВОЛОКНОМ ДЛЯ ПОВЫШЕНИЯ ЭКСПЛУАТАЦИОННЫХ ХАРАКТЕРИСТИК
}

\author{
Ткач Евгения Владимировна', \\ ev_tkach@mail.ru
}

Темирканов Руслан Ильясович 1 , profit288@gmail.com

\author{
Ткач Семен Андреевич2, \\ DS_2009@yandex.ru \\ 1 Национальный исследовательский Московский государственный строительный университет, \\ Россия, 12933, г. Москва, Ярославское шоссе, 26. \\ 2 Открытое Акционерное Общество «РОТ ФРОНТ», \\ Россия, 115184, г. Москва, 2-й Новокузнецкий пер., 13/15.
}

\begin{abstract}
Актуальность. Основной задачей осуществления экологической политики является создание ресурсоэффрективной системы размещения и утилизации промышленных отходов и вторичного сырья, в частности, при производстве строительных материалов и изделий заданных свойств. В рамках данного исследования рассмотрены вопросы, связанные с активацией микрокремнезема, являющегося отходом феерросплавного производства, и способами его применения для модифицирования структуры цементного камня, в частности для тяжелого бетона. Определены механизм процесса структурообразования, способ введения и оптимальный расход добавки для модифрицирования бетонной смеси. С помощью комплексного исследования определены продукты диспергирования микрокремнезема, входящего в состав комплексного модифрикатора. Установлено что процесс действия химической активации минеральных частиц изучен недостаточно, в связи с этим представленные исследования, заключающиеся в поиске решений повышения эксплуатационных характеристик за счет процесса предварительной обработки микрокремнезема щелочной средой рН=10,2 совместно с микроармирующим компонентом, являются актуальными.

Цель: установить положительное действие процесса активации микрокремнезема совместно с микроармирующим компонентом на модифицирование структуры тяжелого бетона для повышения прочностных, деформативных и гидрофризических свойств.

Объект: модифицированный тяжельй бетон на основе активированного микрокремнезема совместно с микроармирующим компонентом.

Методы: рентеенофазовый анализ; физико-химическая активация микрокремнезема водой, обработанной методом электролиза прибором «Мелеста»; ИК-спектроскопия при помощи ИК Фурье спектрометра Varian 640-IR; испьттания на трещиностойкость с помощью сервогидравлической системы ADVANTEST 9; определение марки морозостойкости в климатической камере WK3 180/40; водонепроницаемость определяли в установке УВБ-МГ4.01; водопоглощение определяли, используя электрическую цифрровую печь СНОЛ.

Результаты. Установлено положительное влияние активированного микрокремнезема на свойства тяжелого бетона путем уменьшения содержания вяжущего (иемента) и замены его микродисперсным наполнителем, предварительно активированным щелочной средой с $\mathrm{pH}=10,2$. При этом отмечается повышение прочности на сжатие бетона в возрасте 28 суток на 20,72 МПа в сравнении с контрольным составом. Дальнейщее модифицирование комплексной добавкой (высоководоредуцирующая добавка «MasterGlenium 115» с расходом 1 \% и реакционно-химическая добавка микрокремнезем марки МКУ-95 - 15 \% от массы вяжущего) совместно с базальтовым волокном позволяет улучшить не только физико-механические свойства бетона, но и гидрофизические: водопоглощение - 2 \%; марка по водонепроницаемости - W14; морозостойкость - F600, что дает возможность применять данный состав на практике для получения строительных изделий и конструкций с заданными характеристиками в суровых условиях эксплуатации.
\end{abstract}

\section{Ключевые слова:}

Химическая активация, кремнезем, комплексная добавка, щелочная среда, микроармирующее волокно, модифицирование структуры цементного камня, гидрофизические свойства.

\section{Введение}

Тяжелые бетоны применяются в качестве конструкционных материалов, работающих в суровых условиях эксплуатации при возведении конструкции для зданий и сооружений гражданского, промышленного и специального назначения, что обусловлено их высокой прочностью (до 150 МПа и выше), морозостойкостью $\left(\mathrm{F}_{1}=1000\right)$, плотностью (до $\left.2500 \mathrm{\kappa г} / \mathrm{m}^{3}\right)$, водонепроницаемостью (W20), коррозионной стойко- стью в агрессивных средах. В настоящее время активно проводятся исследования по модифицированию бетонов путем применения химических добавокмодификаторов, а также микро- и нанодисперсных добавок (углеродные нанотрубки, силикатные микросферы, наночастицы оксидов металлов и др.) [1-3].

Преимуществами таких бетонов, по сравнению с традиционными, являются повышенные показатели качества: физико-механические характеристики 
(прочность на сжатие, растяжение при изгибе, трещиностойкость), что связано с повышением плотности и модифицированием структуры цементного камня. Вместе с тем по ряду физико-механических характеристик тяжёлые бетоны не соответствуют современным требованиям, предъявляемым к современным строительным материалам и изделиям на их основе. Для улучшения их эксплуатационных характеристик в последнее время проводятся исследования в направлении модифицирования цементных бетонов путем введения в состав эффективных комплексных добавок, содержащих активные частицы кварца [4-8], а также микроармирующие компоненты [9-13], что является перспективным и ресурсосберегающим направлением развития материаловедения. Имеющиеся в литературе данные по этой проблеме $[5,6,12]$ не позволяют составить целостного представления о влиянии состава бетонной смеси, перевода частиц аморфного микрокремнезема в активную форму в щелочной среде совместно с микроармирующим компонентом в виде полипропиленовой фибры или базальтового волокна на физико-механические свойства. В связи с чем изучение синергетического эффекта воздействия микроармирующего волокна и активированного микрокремнезема на эксплуатационные характеристики тяжелого бетона является актуальным как с фундаментальной, так и с прикладной точки зрения.

Одним из путей решения проблемы повышения характеристик тяжёлых бетонов является введение в состав бетонных смесей активных минеральных добавок - золы уноса, микрокремнезема, золы рисовой шелухи. В этом направлении наиболее перспективные результаты получены в работах [4, 14-17].

В работе [17] авторы приводят результаты исследований бетонной смеси с комплексным модификатором, в состав которой входят: зола рисовой шелухи, зола уноса (неорганическая составляющая), суперпластификатор C-3 или Sika ViscoCrete 5-New (органическая составляющая). Выявлен двоякий механизм действия модификаторов в цементных системах: «химический» фактор - содержание в своем составе диоксида кремния в аморфной модификации и золы рисовой шелухи высокой дисперсности; «физический» фактор - заполнение пространства между кристаллогидратами и сокращение объема свободной воды, приводящий к снижению капиллярной пористости цементного камня и повышению количества гелевых пор. Введение в бетонную смесь золы рисовой шелухи и золы уноса с расходом каждой добавки $10 \%$ совместно с суперпластификатором Sika ViscoCrete 5New расходом 1,5 \% от массы вяжущего вещества повышает в возрасте 28 суток прочность на растяжение при изгибе на $10 \%$, призменную прочность на 19,5 \%, кубиковую прочность при сжатии на 18,2 \%, по отношению к контрольному образцу. Результаты использования данной добавки при получении высокопрочного бетона, которые не вполне соответствуют данным [6], также приведены в работах [4, 16]. Расхождения можно объяснить содержанием кварца в активных минеральных добавках и рекомендуемым расходом комплексной добавки. Другие типы добавок, способствующих улучшению характеристики трещиностойкости бетонов, исследованы в работах [8-11]. В работе [12] исследования основаны на изучении влияния дисперсного армирования полипропиленовым волокном на бетонные элементы. Показано, что введение в мелкозернистую бетонную смесь полипропиленовой фибры с расходом 4 кг $/ \mathrm{M}^{3}$ и длиной элементарного волокна 6 мм способствует повышению предела прочности при сжатии на 25,4 \% и при изгибе на 51,2 \% относительного контрольного состава. При этом отмечается эффект «переармирования» материла при повышении рекомендуемого расхода волокна, что негативно влияет на физикомеханические характеристики исследуемых образцов бетона. Дальнейшее увеличение содержания полипропиленового волокна уменьшает толщину цементного камня между ними, что приводит к расслоению и нарушению сплошности образца. Аналогичное изменение вышеуказанных показателей по сравнению с контрольными образцами наблюдали в работах $[10,11]$.

Более перспективным с точки зрения ресурсоэффективности является использование модификаторов, содержащих в своем составе аморфный микрокремнезем, являющийся более доступным и экологически безопасными отходом ферросплавного производства. Преимуществом его применения является способность позитивно воздействовать на основные эксплуатационные свойства тяжелого бетона: водонепроницаемость, прочность, морозостойкость, износостойкость, выносливость, стойкость к хлоридной, сульфатной коррозии, сопротивляемость к воздействию морской воды и слабых кислот [4, 17]. Ряд модификаторов изучены в работах зарубежных авторов [6-10]. В исследовании [13] показано, что введение комплексной добавки суперпластификатор GleniumACE 430 совместно с микрокремнеземом в бетонную смесь на основе гидравлического вяжущего вещества повышает морозостойкость до 400 циклов и выше, что связано с аморфизацией структуры цементного камня Результаты использования этой добавки при получении высокопрочного тяжелого бетона, которые не вполне соответствуют данным [13], также приведены в работах $[4,15,17]$. Расхождения можно объяснить различным способом введения и дозировкой модификатора. Анализ литературных данных [1-17] по составу и характеристикам бетонов, влиянию комплексных модификаторов на прочностные и эксплуатационные характеристики показал, что вопросы снижения расхода микрокремнезема путем перевода частиц в активную форму и совместное влияние дисперсного армирования на заданные характеристики изучаемого материала до сих пор остаются невыясненными. В связи с этим целью настоящей работы являлась разработка органоминеральной композиции с оптимальным расходом активированного микрокремнезема и микроармирующего волокна для повышения прочностных, деформативных и гидрофизических характеристик тяжелого бетона. 


\section{Материалы и методы исследования}

При исследовании основных прочностных и деформативных характеристик бетонов в качестве вяжущего применялся портландцемент класса ЦЕМ I 42,5Н, производитель ООО «Холсим (Рус) Строи- тельные Материалы» (г. Калуга). Химический и минеральный состав цемента определяли при помощи рентгенофазового и рентгенофлуоресцентного анализов, результаты которых представлены в табл. 1.

Таблица 1. Химический и минеральный состав портландиемента

Table 1. Chemical and mineral composition of Portland cement

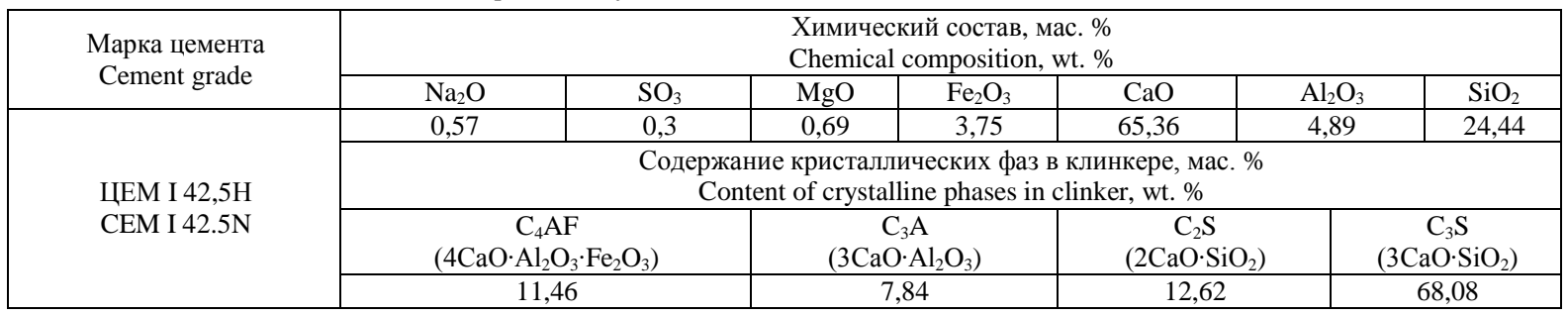

Дисперсный состав, технологические и прочностные характеристики цемента и получаемого из него цементного камня определяли с использованием ситового анализа (контролировали тонкость помола цемента прохождения через сито № 008 с размером ячеек 80 мкм не менее 85 \% массы просеиваемой пробы), пикнометрического метода (истинная плотность цемента составила $\left.3156 \mathrm{\kappa г} / \mathrm{m}^{3}\right)$, определения прочности на изгиб и сжатие (универсальный испытательный блок UPB 86/200, Form+Test, Германия) в соответствии со стандартными методиками. Для определения механической прочности готовили образцы-балочки размером $4 \times 4 \times 16$ см из цементно-песчаного раствора с водоцементным отношением В/Ц $=0,4$. После изготовления образцы в формах содержали 1 сутки в ванне с гидравлическим затвором, в которой обеспечивался режим: относительная влажность воздуха не менее $90 \%$ и температура среды $(20 \pm 2){ }^{\circ} \mathrm{C}$. Через сутки образцы расформовали и затем 27 суток хранили в ванне с водой, температуру в которой контролировали в пределах $(20 \pm 2){ }^{\circ} \mathrm{C}$. После установленного срока выдержки исследуемые образцы-балочки вынимались из ванны, заполненной водой, и через 30 минут испытывали на прочностные характеристики. По результатам испытаний установлено, что цемент соответствует требованиям стандарта по нормируемым показателям: тест на равномерность изменения объема (кольцо Ля Шателье) выдерживает; начало схватывания цементного теста - 197 мин, прочности при сжатии в возрасте 2 и 28 суток - 24,7 и 57,5 МПа, соответственно.

В качестве мелкого заполнителя использовали природный песок с модулем крупности 2,4 с размером частиц от 0,16 до 2,5 мм (поставщик ООО «СТМНеруд», г. Чехов, Московская область). Основной фазой песка являлся $\mathrm{SiO}_{2}$ в кристаллической модификации кварц, тридимит и кристобалит. Содержание примесей не превышало 1,5\%, в состав которых входили глинистые и пылевидные частицы.

В исследовательской части работы крупный заполнитель был представлен в виде гранитного щебня, фракции от 5 до 20 мм производства ООО «Сунский карьер», г. Петрозаводск, который соответствует требованиям по содержанию глинистых, илистых, пыле- видных частиц - 0,95\%; зерен игловатой и пластинчатой и формы - 12,9 \%; марка щебня по морозостойкости - 300; удельная эффективная активность радионуклидов $\left(\mathrm{A}_{э \phi ф}\right)$ - 91 Бк/кг; марка щебня по дробимости - 1400; насыпная плотность - 1355 кг $/ \mathrm{M}^{3}$; марка щебня по истираемости И-1. Максимум в распределении щебня по размерам приходился на 20 мм. Исследуемый заполнитель относится к среднезернистому типу кристаллической структуры.

Для затворения бетонных смесей использовали водопроводную воду с содержанием сульфатов 2500 мг/л (в пересчете на $\mathrm{SO}_{4}$ ) и содержанием всех солей 3600 мг/л. Для сохранения марки по жесткости (Ж1) водоцементное отношение не изменяли $(\mathrm{B} / Ц=0,35)$.

Для повышения подвижности бетонных смесей в них вводили гиперпластификатор «MasterGlenium 115» на основе эфира поликарбоксилата, (производитель ООО «БАСФ Строительные системы», г. Краснодар), расход которого составлял 1 \% от массы вяжущего вещества, рекомендованный производителем модификатор вводили в бетонную смесь одновременно с водой затворения из расчета 4,2 кг на $1 \mathrm{~m}^{3}$ готовой смеси.

В качестве активной минеральной добавки в бетонные смеси вводили микрокремнезем марки МКУ95 (производитель ООО «РУСАЛ Кремний Урал», г. Каменск-Уральский) с интервалом варьирования в количестве от 10 до $20 \%$ от массы вяжущего вещества. Микрокремнезём данной марки является отходом производства ферросилиция, содержащий пылевидные частицы размером от 0,87 до 76,06 мкм. Микрокремнезём вводили в бетонные смеси на этапе смешивания крупного и мелкого заполнителя с цементом. В ряде экспериментов использовали активированный микрокремнезем. Активацию проводили методом электролиза (прибор «Мелеста», производитель ООО «МВП») с применением электродов: катод, выполненный из нержавеющей стали, анод - из титана, покрытого оксидом рутения. В прибор заливали водопроводную воду в объеме 0,8 л, и проводили электролиз в соответствии с паспортными данными прибора до температуры нагревания воды $35^{\circ} \mathrm{C}$.

Для повышения трещиностойкости бетонов в бетонную смесь вводили микроармирующие компонен- 
ты - полипропиленовую фибру или рубленое базальтовое волокно (ООО «Европолис», г. Дубна, Московская область), на этапе сухого перемешивания вяжущего (портландцемента) совместно с мелким и крупным заполнителем.

Для испытания на прочностные и гидрофизические свойства бетона использовалось следующее лабораторное оборудование: универсальный испытательный блок UPB 86/200, сервогидравлическая система ADVANTEST 9, климатическая камера WK3 180/40, установка УВБ-МГ4.01, электрическая цифровая печь СНОЛ.

\section{Результаты и их обсуждение}

Поведение кремнезема в щелочной среде и способ перевода частиц в активную форму изучались в данной работе путем применения в качестве воды затворения водопроводной воды, предварительно обработанной электролизером. Впервые д-р техн. наук, профессор B.М. Бахир в 1972 г. открыл неизвестную на тот момент закономерность: модели католита и анолита, приготовленные путем растворения в воде химических реагентов [18, 19], по своим физическим, химическим параметрам и реакционной способности сильно отличаются от анолита и католита, полученных в электрохимическом диафрагменном реакторе из слабоминерализованной воды. Дальнейшее исследование данного процесса привело к выводу, что полученные модели при обработке воды отличаются от растворов стабильных кислот или щелочей присутствием периода релаксации и являются электрохимически активированными растворами (водой). Разработанная методика электрохимической активации характеризуется повышенными показателями водородного потенциала, окислительновосстановительного потенциала, электропроводности, физико-химических параметров.

По мнению автора, использование данной воды возможно в качестве реакционной среды с целью экономии энергии, повышения качества конечного материала, управления сложными физикохимическими реакциями, что подтверждается и в работах других исследователей [20, 21]. Для проведения лабораторных исследований в качестве электролизера применялся прибор «Мелеста» (ТУ 5156-00232064511-07, сертификат соответствия № ТC СRU.AЯ36.B.00661 Серия RU № 0136939), производи- тель ООО МВП «Мелеста», г. Уфа, принципиальная схема которого представлена на рис. 1.

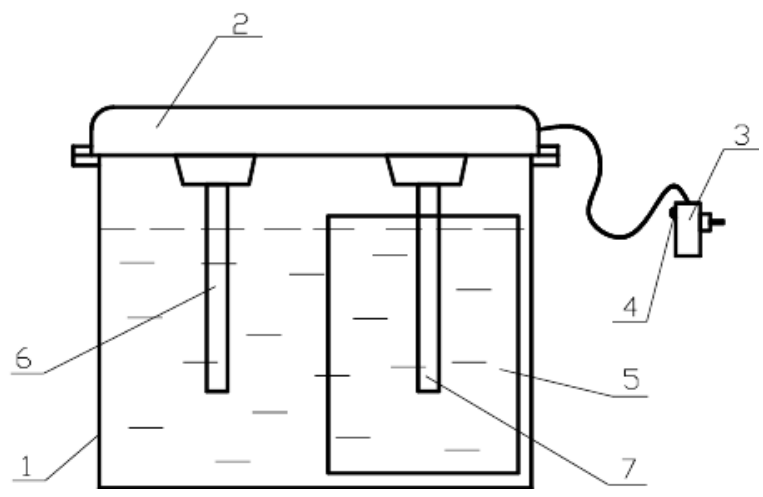

Pис. 1. Схема устройства прибора «Мелеста», где: 1 - основная емкость; 2 - съемная верхняя крышка; 3 - блок питания с предохранителем ВП4-5 3.15 A; 4 - световой индикатор; 5 - съемная внутренняя емкость с диафрагмой; 6-катод; 7 -анод

Fig. 1. Diagram of the device "Melesta», where: 1 - main vessel; 2 - removable top cover; 3 - power supply unit with fuse VP4-5 3.15 A; 4 - light indicator; 5 - removable inner container with a diaphragm; 6 - cathode; 7 - anode

Катод в приборе выполнен из нержавеющей стали, а анод - из титана, покрытого оксидом рутения. В прибор заливали водопроводную воду в объеме 0,8 л, и проводили электролиз в соответствии с паспортными данными прибора до температуры нагревания воды $35{ }^{\circ} \mathrm{C}$. По результатам обработки воды в основной емкости (позиция 1, рис. 1) образовалась щелочная среда с $\mathrm{pH}=10,2$, а во внутренней емкости (позиция 5, рис. 1) - кислая среда с $\mathrm{pH}=2,6$. Полученные результаты согласуются с трудами ученых [18-24]. Следующим этапом изучалось воздействие полученного католита на микрокремнезем с его предварительной выдержкой до 20 минут в щелочной среде, связанное с переводом частиц кремнезема в активную форму, и введение совместно с гиперпластификатоpoм «MasterGlenium 115» и водой затворения на этапе сухого смешивания мелкого и крупного заполнителя, вяжущего вещества и волокна. Механизм растворения кремнезема в воде в присутствии гидроксилионов представлен на рис. 2.

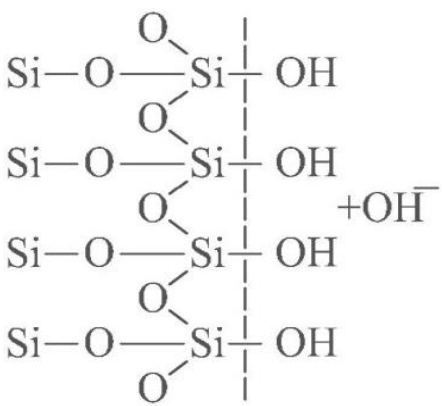

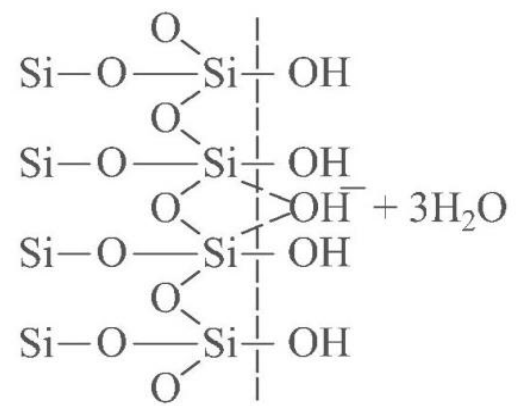

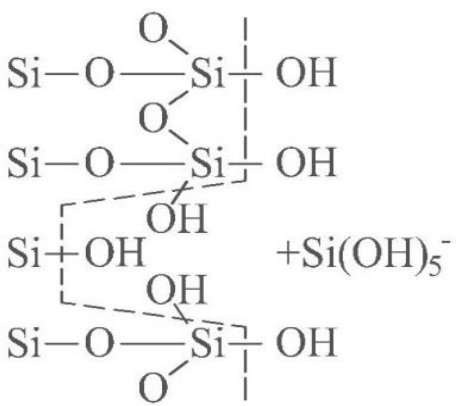

Рис. 2. Принципиальная схема растворения кремнезема в воде в присутствии гидроксил-ионов. Пунктирная линия показывает поверхность раздела между водой (справа) и кремнеземом (слева) [25]

Fig. 2. Schematic diagram of silica dissolution in water in the presence of hydroxyl ions. The dotted line shows the interface between water (right) and silica (left) [25] 
Из химических реакций (рис. 2.) следует, что первоначально происходит процесс адсорбции иона $\mathrm{OH}^{-}$, за ним следует переход поверхностного атома кремния в раствор в виде силикат-иона, который при $\mathrm{pH}$ 10,2 гидролизуется с образованием ионов $\mathrm{OH}^{-}$и молекул растворимого кремнезема $\mathrm{Si}(\mathrm{OH})_{4}$, что согласуется с работой [26]. В данной области значений $\mathrm{pH}$ растворимый аморфный кремнезем находится в равновесии как с нейтральным мономером, так и с силикат-ионами:

$$
\begin{gathered}
\left(\mathrm{SiO}_{2}\right)_{\mathrm{x}}+2 \mathrm{H}_{2} \mathrm{O}=\mathrm{Si}(\mathrm{OH})_{4}+\left(\mathrm{SiO}_{2}\right)_{\mathrm{x}-1} ; \\
\left.\mathrm{Si}(\mathrm{OH})_{4}+\mathrm{OH}^{-}=\mathrm{Si}(\mathrm{OH})_{5}^{-} \text {(или } \mathrm{HSiO}_{3}^{-}\right) .
\end{gathered}
$$

Проанализировав представленные выше теоретические данные работ [25, 26], связанные с поведением аморфного кремнезема в щелочной среде при $\mathrm{pH}=10,2$, было принято решение использовать в качестве среды предварительно обработанную методом электролиза водопроводную воду, которая содержит гидрокарбонаты кальция и магния.

Далее эффективность применения добавок оценивали по экспериментально установленным показателям механических и физико-химических свойств модифицируемых составов бетона. Для определения оптимального расхода высокореакционной добавки в виде микрокремнезема в составе бетонной смеси с целью повышения физико-механических характеристик бетона был установлен интервал варьирования расхода добавки в количестве $5 \%$ от массы вяжущего. При введении микронаполнителя расход цемента уменьшали в связи с высокой вероятностью образования локальных агрегатов из цементных частиц, которые непосредственно взаимно контактируют в процессе смешивания с водой. Удаленность частиц вяжущего относительно друг друга на расстояние диаметра частиц микрокремнезема способствует повышению микрооднородности структуры и прочности модифицированной цементной матрицы [27]. Оптимальное содержание комплексной добавки (высоководоредуцирующая добавка «MasterGlenium 115» плюс реакционно-химическая добавка микрокремнезем марки МКУ-95) определяли по изменению предела прочности на сжатие в возрасте 28 суток нормального твердения, по 3 образца для каждого состава, размером $150 \times 150 \times 150$ мм. Исследуемые составы и результаты испытания, представленные в табл. 2, свидетельствуют о том, что оптимальное содержание микрокремнезема составляет $15 \%$ [состав 4], что подтверждается превышением прочности на $39,5 \%$ относительно контрольного образца.

Представленный на рис. 3 ИК-спектр многократного нарушения полного внутреннего отражения обработанного микрокремнезема кислой и щелочной средой по положению пиков и полос поглощения в спектрах пропускания в диапазоне $500-4500 \mathrm{~cm}^{-1}$ совпадает с золем ортокремневой кислоты. В диапазоне $500-600 \mathrm{~cm}^{-1}$ полоса поглощения характерна для деформационных колебаний связей внутри кремнекислородных сочленений и их группировок. За счёт сим- метричных колебаний $\mathrm{Si}-\mathrm{O}-\mathrm{Si}$ связей (колебаний кремнекислородных тетраэдров друг относительно друга) возникает полоса поглощения 700-900 $\mathrm{cm}^{-1}$, что свидетельствует об их полной полимеризации. В спектральной области 1000-1290 см${ }^{-1}$ присутствует глубокая полоса поглощения, связанная с поперечными, смешанными и продольными и колебаниями $\mathrm{Si}-\mathrm{O}-\mathrm{Si}$ связей, с минимумом пропускания при 1080 $\mathrm{CM}^{-1}[28]$.

Таблица 2. Исследуемые составы бетона с учетом расхода материалов и результаты испытаний

Table 2. Investigated concrete compositions, taking into account the consumption of materials, and test

\begin{tabular}{|c|c|c|c|c|c|}
\hline \multirow[b]{2}{*}{$\begin{array}{l}\text { Компоненты бетонной } \\
\text { смеси } \\
\text { Concrete components }\end{array}$} & \multicolumn{5}{|c|}{$\begin{array}{c}\text { Состав и расход на } 1 \mathrm{~m}^{3} \text { смеси, кг/ } / \mathrm{m}^{3} \\
\text { Composition and consumption per } 1 \mathrm{~m}^{3} \\
\text { of mixture, } \mathrm{kg} / \mathrm{m}^{3}\end{array}$} \\
\hline & 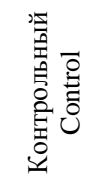 & № 1 & № 2 & № 3 & № 4 \\
\hline $\begin{array}{l}\text { Цемент ЦЕМ I 42,5H } \\
\text { Cement CEM I 42,5N }\end{array}$ & 421 & 377 & 356 & 337 & 358 \\
\hline $\begin{array}{l}\text { Крупный заполнитель - } \\
\text { гранитный щебень } \\
\text { Large aggregate - granite } \\
\text { rubble }\end{array}$ & 951 & 951 & 951 & 951 & 951 \\
\hline Вода/Water & 148 & 148 & 148 & 148 & - \\
\hline $\begin{array}{l}\text { Мелкий заполнитель - песок } \\
\text { Fine aggregate - sand }\end{array}$ & 844 & 844 & 844 & 844 & 844 \\
\hline $\begin{array}{l}\text { Микрокремнезем МКУ-95 } \\
\text { Microsilica MKU-95 }\end{array}$ & - & 41 & 64 & 85 & 64 \\
\hline $\begin{array}{l}\text { Гиперпластификатор } \\
\text { «MasterGlenium 115» } \\
\text { Hyperplasticizer } \\
\text { «MasterGlenium 115» } \\
\end{array}$ & 4,21 & 4,21 & 4,21 & 4,21 & 4,21 \\
\hline $\begin{array}{l}\text { Вода, обработанная мето- } \\
\text { дом электролиза с } \mathrm{pH}=10,2 \\
\text { Water treated by electrolysis } \\
\text { method with } \mathrm{pH}=10,2\end{array}$ & - & - & - & - & 148 \\
\hline $\begin{array}{l}\mathrm{B} / \mathrm{T}(Ц+\mathrm{MK}) \\
\text { Water-solid ratio (cement+ } \\
\text { microsilica) }\end{array}$ & 0,351 & 0,351 & 0,351 & 0,351 & 0,351 \\
\hline $\begin{array}{l}\text { Средняя плотность, кг/. }{ }^{3} \\
\text { Average density, } \mathrm{kg} / \mathrm{m}^{3}\end{array}$ & 2433,1 & 2453,2 & 2458,8 & 2476,3 & 2460,2 \\
\hline $\begin{array}{l}\text { Прочность на сжатие в } \\
\text { возрасте } 28 \text { суток, МПа } \\
\text { Compressive strength at the } \\
\text { age of } 28 \text { days, MPa }\end{array}$ & 52,41 & 57,49 & 60,87 & 50,32 & 73,13 \\
\hline
\end{tabular}
results

В соединениях, в составе которых присутствует диоксид кремния $\left(\mathrm{SiO}_{2}\right)$, в ИК-спектрах присутствуют широкие полосы поглощения в диапазоне 1630-1640 и 3350-3550 $\mathrm{cm}^{-1}$, что соответствуют валентным v- и деформационным $\delta$-колебаниям адсорбированных молекул воды. Полоса поглощения $1625 \mathrm{~cm}^{-1}$ соответствует $\delta$-колебаниям моно- или димерномолекулярно адсорбированной $\mathrm{H}_{2} \mathrm{O}$, а полоса при максимуме $3540 \mathrm{~cm}^{-1}$ - о наличии ОН-группы. Анализ полученных ИК-спектров в виде полос колебаний подтверждает наличие в синтезированной системе идентифицируемых катионных ОН-групп, адсорбированной воды и валентных связей $\mathrm{Si}-\mathrm{O}$. 


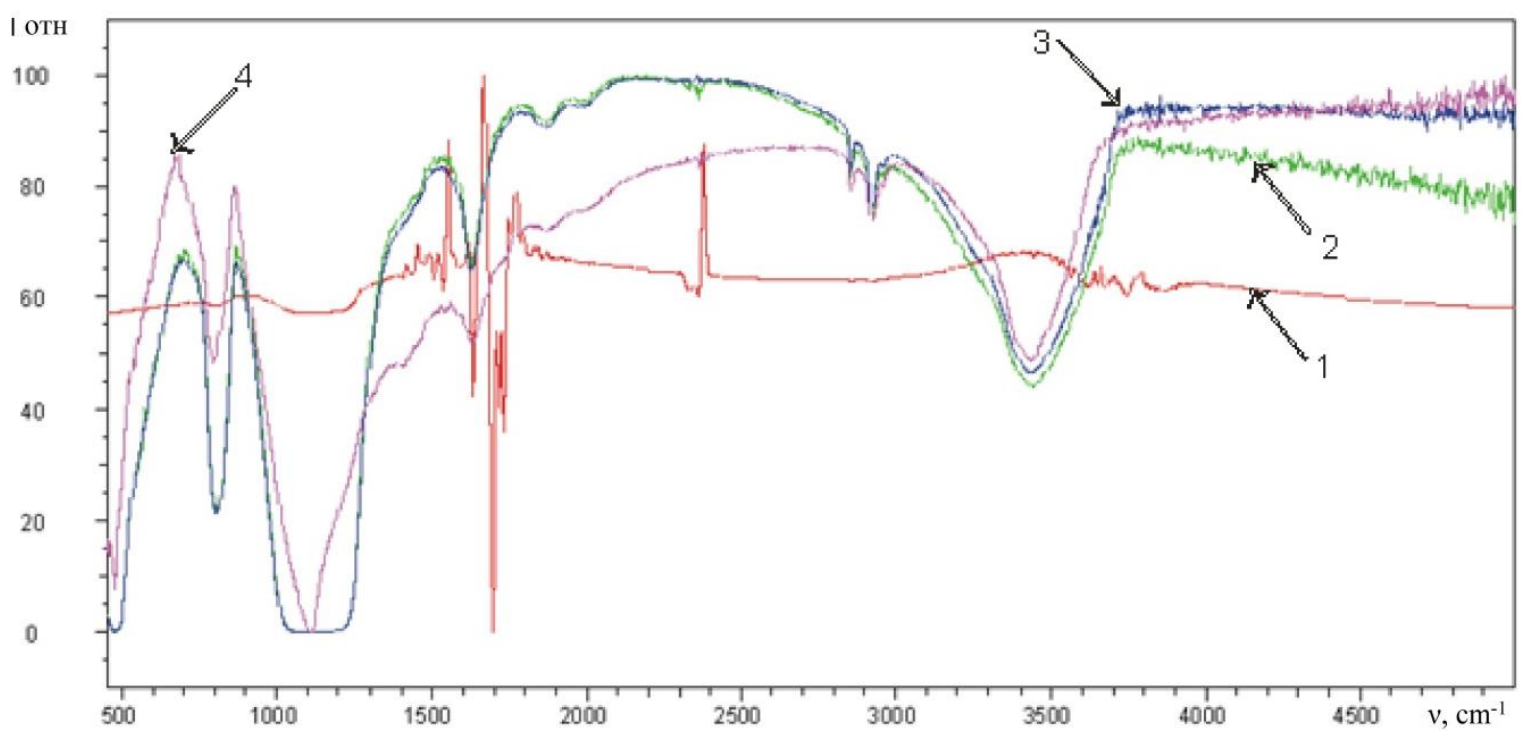

Pис. 3. ИК спектры образиов: 1 - микрокремнезем МКУ-95 (аморфный); 2 - микрокремнезем МКУ-95, обработанный кислой средой; 3 - микрокремнезем МКУ-95, обработанный щелочной средой; 4 - квариевое стекло (эталон)

Fig. 3. IR spectra of samples: 1 - microsilica MKU-95 (amorphous); 2 - microsilica MKU-95, treated with acidic medium; 3 - microsilica MKU-95, treated with alkaline medium; 4 - quartz glass (standard)

Для дальнейших исследований, с учетом особенности влияния кислой среды на коррозию арматуры в железобетонных изделиях, было принято решение осуществлять обработку микрокремнезема только водой, полученной методом электролиза с $\mathrm{pH}=10,2$. Таким образом, можно сделать вывод, что при обработке микрокремнезема различными средами получили практически одинаковые ИК-спектры, близкие к эталону (кварцевое стекло) и отличные от аморфного микрокремнезема, что является доказательством химической активации микрокремнезема. Установлено, что на процесс диспергирования микрокремнезема до состояния кислоты ортокремниевой $\mathrm{Si}(\mathrm{OH})_{4}$ и ее димеров влияют в кислой среде ионы оксония $\mathrm{H}_{3} \mathrm{O}^{+}$, а в щелочной среде ионы гидроксилов $\mathrm{OH}^{-}$.

В ходе изучения нагрузок, действующих на изделия из тяжелого бетона, в частности, на примере железобетонных шпал, работающих в суровых условиях эксплуатации, особым критерием стоит отметить сопротивление к динамическим воздействиям. Присутствие в материале трещин от макро- до субмикромасштабного размера и фрактальной иерархии процесса трещинообразования создает предпосылки для эффективного дисперсного армирования материала волокнами [27]. Для дальнейшего исследования влияния армирующих элементов на характеристику трещиностойкости тяжелого бетона в состав смеси вводили рубленное базальтовое волокно и полипропиленовую фибру, которые хорошо себя зарекомендовали [8-10].

Для испытаний прочностных и деформативных характеристик образцов модифицированного бетона использовались стандартные методы исследований. В дальнейших экспериментах использовались образцыпризмы с размером ребер $70 \times 70 \times 280$ мм, составы которых представлены в табл. 3.
Таблица 3. Расход материалов для разработанных составов бетонных смесей

Table 3. Consumption of materials for the developed concrete mixes

\begin{tabular}{|c|c|c|c|c|c|c|c|}
\hline \multirow{2}{*}{$\begin{array}{l}\text { Вводимые компоненты } \\
\text { Input components }\end{array}$} & \multicolumn{7}{|c|}{$\begin{array}{c}\text { Расход компонентов на } 1 \mathrm{~m}^{3}, \mathrm{\kappa г} \\
\text { Component consumption per } 1 \mathrm{~m}^{3}, \mathrm{~kg}\end{array}$} \\
\hline & № 1 & \begin{tabular}{|l|} 
№ \\
\end{tabular} & \begin{tabular}{|l|} 
№ 3 \\
\end{tabular} & № 4 & \begin{tabular}{|l|} 
№ 5 \\
\end{tabular} & \begin{tabular}{|l|} 
№ \\
\end{tabular} & № 7 \\
\hline $\begin{array}{l}\text { ЦЕM I 42,5H } \\
\text { Cement CEM I 42,5N }\end{array}$ & \multicolumn{7}{|c|}{358} \\
\hline $\begin{array}{l}\text { Крупный заполнитель - } \\
\text { гранитный щебень } \\
\text { Large aggregate - granite } \\
\text { rubble }\end{array}$ & \multicolumn{7}{|c|}{951} \\
\hline $\begin{array}{l}\text { Обработанная вода с } \\
\mathrm{pH}=10,2 \\
\text { Treated water with } \mathrm{pH}=10,2\end{array}$ & \multicolumn{7}{|c|}{148} \\
\hline $\begin{array}{l}\text { Мелкий заполнитель - } \\
\text { песок } \\
\text { Fine aggregate - sand }\end{array}$ & \multicolumn{7}{|c|}{842} \\
\hline $\begin{array}{l}\text { Микрокремнезем МКУ-95 } \\
\text { Microsilica MKU-95 }\end{array}$ & \multicolumn{7}{|c|}{62} \\
\hline $\begin{array}{l}\text { Гиперпластификатор } \\
\text { «MasterGlenium 115» } \\
\text { Hyperplasticizer } \\
\text { «MasterGlenium 115» }\end{array}$ & \multicolumn{7}{|c|}{4,3} \\
\hline $\begin{array}{l}\text { Фибра полипропиленовая } \\
\text { (ППФ) } \\
\text { Polypropylene fiber (PPF) }\end{array}$ & - & - & - & - & 4,6 & 6,83 & 9,2 \\
\hline $\begin{array}{l}\text { Базальтовое волокно (БВ) } \\
\text { Basalt fiber (BF) }\end{array}$ & - & 13,8 & 20,6 & 27,5 & - & - & - \\
\hline $\begin{array}{l}\text { B/T (Ц+MК) } \\
\text { Water-solid ratio } \\
\text { (cement+ microsilica) }\end{array}$ & \multicolumn{7}{|c|}{0,351} \\
\hline
\end{tabular}

При проведении испытаний на трещиностойкость модифицированного бетона, путем введения в бетонную смесь микроармирующего волокна и микрокремнезема, предварительно обработанного щелочной средой, необходимо соблюдение следующих требований: температурный режим окружающей среды $t=20 \pm 5^{\circ} \mathrm{C}$ и относительная влажность не менее $50 \%$. Предварительно произвели два цикла нагружения-разгружения с нагрузкой, 
равной $10 \%$ от ожидаемой максимальной нагрузки. При проведении неравновесных испытаний образцы-призмы нагружали непрерывно до момента их разделения на две части, зафиксировав при этом максимальное значение нагрузки $F_{c}^{*}$ - динамическое начало движения магистральной трещины. Результаты испытаний представлены в табл. 4, а графики нагружения на рис. 4.

Таблица 4. Испытания на трещчиностойкость модифицированного бетона

Table 4. Crack resistance tests of modified concrete

\begin{tabular}{|l|c|c|c|c|c|c|c|}
\hline \multirow{2}{*}{$\begin{array}{l}\text { Показатель } \\
\text { Indicator }\end{array}$} & \multicolumn{7}{|c|}{ Маркировка образцов } \\
\cline { 2 - 8 } & № 1 & № 2 & № 3 & № 4 & № 5 & № 6 & № 7 \\
\hline $\begin{array}{l}\text { Нагрузка, кH } \\
\text { Load, kN }\end{array}$ & 2,235 & 2,609 & 2,741 & 2,571 & 2,804 & 2,933 & 2,739 \\
\hline $\begin{array}{l}\text { Напряжение, } \\
\text { MПа } \\
\text { Voltage, MPa }\end{array}$ & 6,401 & 7,180 & 7,542 & 7,074 & 7,709 & 8,064 & 7,532 \\
\hline
\end{tabular}

Анализ полученных опытных данных (табл. 4) показал, что образцы-призмы из тяжелого бетона с базальтовым волокном показали повышенную способность сопротивления приложенной нагрузки. При этом требуемая нагрузка для разрушения и зафиксированное напряжение образца с расходом базальтового волокна возросли на 30 \% по отношению к контрольному (без микроармирующего наполнителя) и на 7 \% с полипропиленовой фиброй расходом $0,75 \%$. Полученные результаты свидетельствуют о повышении сцепления между цементно-песчаной матрицей и введёнными в бетонную смесь базальтовыми волокнами, обладающими лучшей микроармирующей способностью и релаксацией напряжений на поверхностях контакта «матрица-заполнитель» в сравнении с полипропиленовой фиброй, что согласуется с данными работ [12-16, 27].

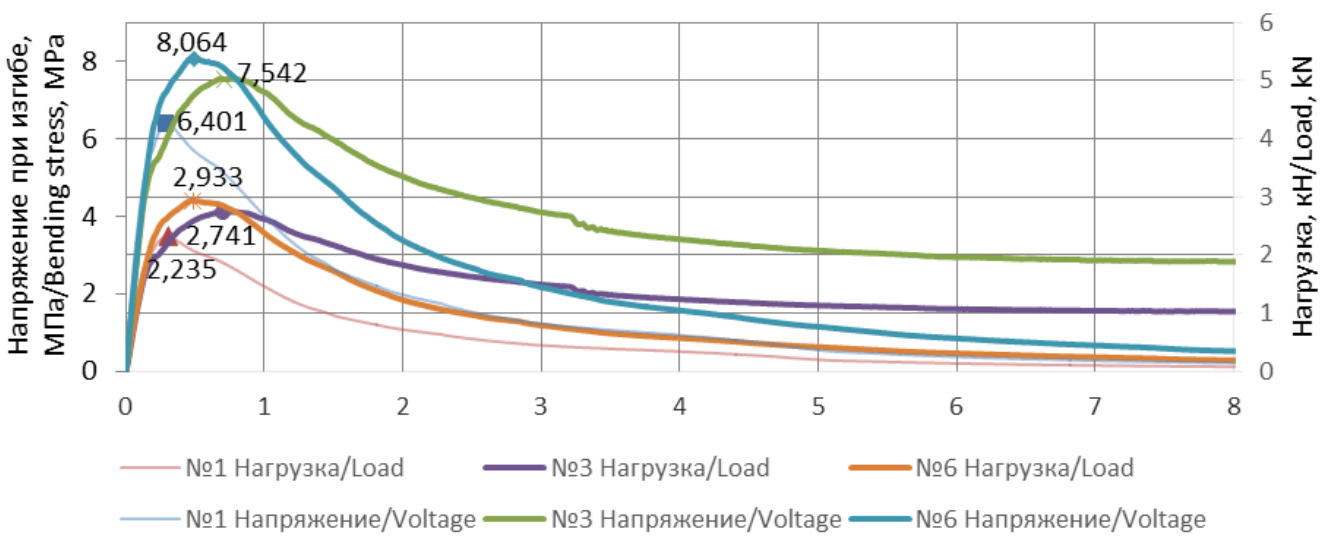

Pис. 4. Нагружение образиов-призм из модифицированного тяжелого бетона: № 1 - контрольный состав; № 3 - с полипропиленовой фиброй (0,75\%); № $6-c$ базальтовым волокном $(0,75 \%)$

Fig. 4. Loading of specimens-prisms made of modified heavy concrete: no. 1 - control composition; no. 3 - with polypropylene fiber $(0,75 \%)$; no. 6 - with basalt fiber $(0,75 \%)$

Таблица 5. Результаты деформативных и прочностных характеристик образиов-призм исследуемых составов модифииированных бетонов

Table 5. Results of the deformation and strength characteristics of the modified concrete specimensprisms

\begin{tabular}{|c|c|c|c|}
\hline $\begin{array}{c}\text { Марки- } \\
\text { ровка } \\
\text { образца } \\
\begin{array}{c}\text { Sample } \\
\text { mark }\end{array}\end{array}$ & $\begin{array}{c}\text { Условный коэф- } \\
\text { фициент интен- } \\
\text { сивности напря- } \\
\text { жений, МПа·м } \\
\text { Conditional stress } \\
\text { intensity factor, } \\
\text { МРa·m }\end{array}$ & $\begin{array}{c}\text { Макси- } \\
\text { мальная } \\
\text { нагрузка, } \\
\text { кН } \\
\text { Maximum } \\
\text { load, kN }\end{array}$ & $\begin{array}{c}\text { Максималь- } \\
\text { ное напряже- } \\
\text { ние при изги- } \\
\text { бе, МПа } \\
\text { Махimum } \\
\text { bending stress, } \\
\text { МРa }\end{array}$ \\
\hline $\begin{array}{l}\text { Кон- } \\
\text { трольный } \\
\text { Соntrol }\end{array}$ & 0,05886 & 2,235 & 6,401 \\
\hline $\begin{array}{l}\text { ППФ/РРF } \\
0,75 \%\end{array}$ & 0,06920 & 2,741 & 7,542 \\
\hline $\begin{array}{l}\text { БВ/ВF } \\
0,75 \%\end{array}$ & 0,07435 & 2,933 & 8,064 \\
\hline
\end{tabular}

Анализ рис. 4 показал длительный характер ширины раскрытия магистральной трещины образцовпризм (рис. 4, состав № 3, 6), армированных волокнами, по сравнению с контрольным (рис. 4, состав № 1) Это свидетельствует о том, что разрушение сопровождается высокой задействованностью введенных волокон. Повышенная степень вязкости разрушения дисперсно-армированных образцов характеризуется достаточно замедленной ниспадающей ветвью, отображенной на графиках (рис. 4, состав № 3,6). Повышенная концентрация новообразований вдоль микроармирующих волокон обуславливает значительную разницу в полученных результатах, что согласуется с результатами работ [12-16, 27].

Полученные результаты деформативных и прочностных характеристик исследуемых образцов-призм отображены в табл. 5.

Полученные результаты, представленные в табл. 5, показали, что у образцов бетона, содержащих базальтовое волокно (состав 6), повысились показатели максимальной нагрузки и условного коэффициента интенсивности напряжений на 31,23 и 24,21 \% соответственно, а напряжение при изгибе - на 26,3 \% в сравнении с контрольным (состав 1). При этом наблюдается повышение деформативных и прочностных характеристик на 7,5 \% относительно состава 3 (с полипропиленовой фиброй), что объясняется дисперсным армированием тяжелого бетона базальтовым волокном, повышающим физико-механические характеристики за счет положительного влияния на 
структуру бетона при нагружении - выравнивание напряжения в структуре бетона и их перераспределение между составляющими цементной матрицы, снижение концентрации напряжений в зоне макродефектов и ограничение распространения роста магистральной трещины, что согласуется с данными [27].

Таблица 6. Результаты испьтаний бетона на водопоглощение и водонепроницаемость

Table 6. Results of concrete tests for water absorption and water resistance

\begin{tabular}{|c|c|c|c|c|}
\hline 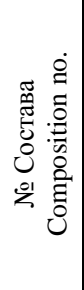 & $\begin{array}{c}\text { Модификатор, \% } \\
\text { от массы цемента для } \\
\text { микрокремнезема и \% } \\
\text { от объема для волокна } \\
\text { Modifier, \% by weight } \\
\text { of cement for microsilica } \\
\text { and \% by volume for fiber }\end{array}$ & $\begin{array}{ll}0 & 0 \\
0 & 0 \\
0 & 0 \\
0 & 0 \\
0 & 0 \\
0 & 0 \\
0 & 0 \\
0 & 0 \\
0 & 0 \\
0 & 0 \\
0 & 0 \\
0 & 0 \\
0 & 3\end{array}$ & 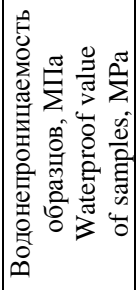 & 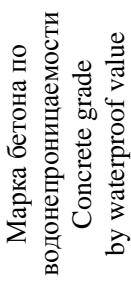 \\
\hline 1 & \begin{tabular}{|l|} 
Контрольный, без \\
модификаторов \\
Control, no modifiers \\
\end{tabular} & 3,5 & 0,8 & W8 \\
\hline 2 & $\begin{array}{l}\text { MKУ-95, } 15 \% \\
\text { MKU-95, } 15 \% \\
\end{array}$ & 2,3 & 1,0 & W10 \\
\hline 3 & $\begin{array}{l}\text { Активированный МКУ-95, } \\
15 \% \\
\text { Activated MKU-95, } 15 \%\end{array}$ & 2,15 & 1,0 & W10 \\
\hline 4 & $\begin{array}{l}\text { Активированный МКУ-95, } \\
15 \% \text { \% ППФ, 0,75 \% } \\
\text { Activated MKU-95, 15\%; } \\
\text { PPF, 0,75\% }\end{array}$ & 2,1 & 1,2 & W12 \\
\hline 5 & $\begin{array}{l}\text { Активированный МКУ-95, } \\
15 \% \text {; БВ, 0,75 \% } \\
\text { Activated MKU-95, } 15 \% \text {; } \\
\text { BF, } 0,75 \%\end{array}$ & 2,0 & 1,2 & W14 \\
\hline
\end{tabular}

Для повышения стойкости строительных изделий и конструкций в суровых условиях эксплуатации необходимо также улучшить гидрофизические свойства бетона, такие как водонепроницаемость, водопоглощение и морозостойкость, которые значительно повышают долговечность и безотказный срок службы конструкций. Результаты стандартных испытаний на водопоглощение и водонепроницаемость бетона представлены в табл. 6. Анализ полученных данных табл. 6 показывает, что бетон, в состав которого входит активированный микрокремнезем совместно с базальтовым волокном (состав 5), имеет пониженные показатели водопоглощения в сравнении с контрольным (состав 1) на 57 \%. Водонепроницаемость модифицированного бетона (состав 5) повысилась до W14 в сравнении с контрольным составом бетона (без модификаторов, состав 1), на 4 ступени относительно составов без волокна (составы 2, 3) и на 2 ступени относительно состава с ПФ (состав № 4).

Повышение гидрофизических свойств образцов бетона (состав 4) объясняется улучшением качества структуры модифицированного цементного камня и бетона на его основе в присутствии комплексного модификатора (высоководоредуцирующая добавка «MasterGlenium 115» плюс реакционно-химическая добавка микрокремнезем марки МКУ-95) совместно с базальтовым волокном, за счет дробления макропор под действием ПАВ («MasterGlenium 115») уменьшается развитие капиллярных трещин, развивается микропористость с размерами пор 0,1 мкм, то есть близкая к контракционной, что согласуется с выводами работ [ 5-7, 27, 29].

Для проведения испытаний на морозостойкость применялся первый базовый метод при многократном замораживании и оттаивании в водонасыщенном состоянии в соответствии с методикой, в которой установлены условия испытания: вода для насыщения и оттаивания с температурой $20 \pm 2{ }^{\circ} \mathrm{C}$ и с температурой замораживания минус $18 \pm 2{ }^{\circ} \mathrm{C}$. Определение марки морозостойкости бетона проводилось на образцах с ребрами $100 \times 100 \times 100$ мм в возрасте 28 суток. Результаты испытаний на морозостойкость исследуемых бетонов представлены на рис. 5.

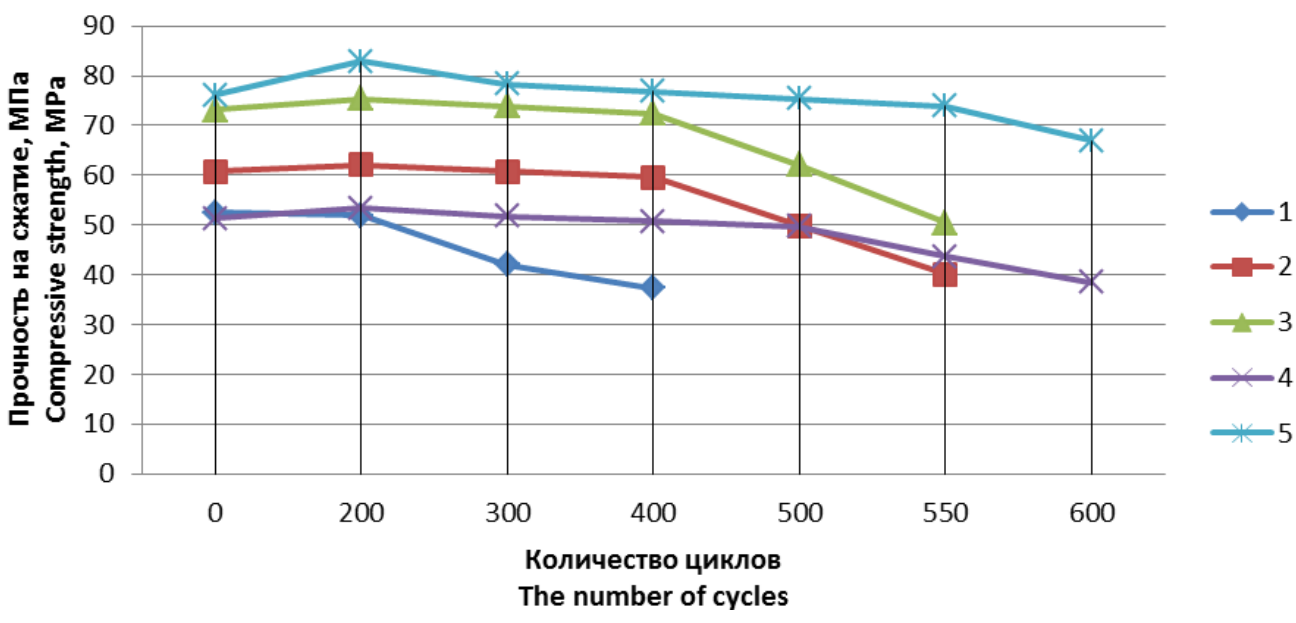

Pис. 5. Графическая интерпретация результатов испытаний образцов тяжелого бетона на морозостойкость: 1 - контрольный состав; 2 - МКУ-95 с расходом $15 \%$; 3 - активированный МКУ-95 с расходом $15 \%$; 4 - активированный МКУ-95 с расходом $15 \%$, ППФ с расходом 0,75\%; 5 - активированный МКУ-95 с расходом $15 \%$; БВ с расходом $0,75 \%$

Fig. 5. Graphic interpretation of the results of testing heavy concrete samples for frost resistance: 1 - control composition; 2 - MKU-95, $15 \%$ flow rate; 3 - activated MKU-95, $15 \%$ flow rate; 4 -activated MKU-95, $15 \%$ flow rate, PPF, $0,75 \%$ flow rate; 5 -activated $M K U-95,15 \%$ flow rate; $B F, 0,75 \%$ flow rate 
Анализ данных по морозостойкости позволил сделать следующие выводы:

- полученные результаты испытаний контрольного (состава 1) бетона показали, что, начиная с 400 циклов, в образцах отмечалось снижение массы на 5,5 \% и кубиковой прочности на $29 \%$;

- при 550-600 циклах глубина разрушения образцов с ППВ и активированным микрокремнеземом (состав 4) становилась критической - она понизила прочностные характеристики более чем на 25 \%, а снижение массы достигло 4,2 \%.

- высокая морозостойкость (состав 5) с оптимальным расходом активированного микрокремнезема марки МКУ-95 с расходом 15 \% и БВ 0,75 \% характеризуется потерей массы до $3 \%$ и прочности на $12 \%$ при 600 циклах испытания, что обусловлено созданием замкнутой мелкопористой структуры цементного камня и высокой его водонепроницаемостью [30].

Таким образом, можно резюмировать, что предлагаемые составы бетонов обеспечивают получение эффективных бетонов с повышенными эксплуатационными показателями: прочность на сжатие в возрасте 28 сут - 73 МПа; условный коэффициент интенсивности напряжений - 0,07435 МПа·м; водопоглощение - 2 \%; марка по водонепроницаемости $\mathrm{W} 14$; морозостойкость - F600, что позволяет рекомендовать их к эксплуатации в суровых климатических условиях РФ, в частности, в экстремально холодном (ЭХл, ЕС) и холодном (Хл, С) типах климата, покрывающих более $60 \%$ ее территории.

\section{Выводы}

1. Обосновано и экспериментально доказано положительное действие предварительной подготовки минеральной добавки-микрокремнезема, являющейся отходом ферросплавного производства, на процессы структурообразования гидратационной системы твердения. Раскрыта сущность физико-химической активации микрокремнезема в щелочной среде $\mathrm{pH}=10,2$, обогащенной гидроксильными группами $\mathrm{OH}^{-}$, связанная с переходом поверхностного атома кремния в раствор в виде силикат-иона, который гидролизуется с образованием ионов $\mathrm{OH}^{-}$и молекул растворимого кремнезема $\mathrm{Si}(\mathrm{OH})_{4}$, что подтверждается ИКспектроскопией с помощью которой зафиксировано образование ортокремниевой кислоты $\mathrm{Si}(\mathrm{OH})_{4}$.

\section{СПИСОК ЛИТЕРАТУРЫ}

1. Модификация цементных бетонов многослойными углеродными нанотрубками / Г.И. Яковлев, Г.Н. Первушин, А. Корженко, А.Ф. Бурьянов, И.А. Пудов, А.А. Лушникова // Строительные материалы. - 2011. - № 2. - С. 47-51.

2. Preparation of $\mathrm{TiO}_{2}$ coated silicate micro-spheres for enhancing the light diffusion property of polycarbonate composites / Y. Zhao, P. Ding, C. Ba, A. Tang, N. Song, Y. Liu, L. Shi // Displays. 2014. - V. 35. - № 4. - P. 220-226.

3. Осаждение металлических наночастиц из коллоидных растворов импульсно-периодическим лазерным излучением / А.А. Антипов, С.М. Аракелян, С.В. Кутровская, А.О. Кучерик, Д.С. Ногтев, В.Г. Прокошев // Перспективные материалы. 2011. - № 10. - С. 200-205.
2. Экспериментально подтверждено, что при оптимальном содержании комплексной добавки в составе модифицированного бетона (высоководоредуцирующая добавка «MasterGlenium 115» с расходом 1 \% плюс реакционно-химическая добавками микрокремнезем марки МКУ-95 - $15 \%$ от массы вяжущего) повышается прочность на сжатие на 39,5 \% в сравнении с контрольным, что связано с образованием продуктов гидролиза активированного микрокремнезема, которые концентрируют вокруг себя новообразования, формирующие коллоидную систему, что способствует повышенной гидратации цементных зерен.

3. Определен характер разрушения образцов-призм из модифицированного бетона совместно с БВ $0,75 \%$, и установлены его физико-механические характеристики, которые значительно превосходят контрольный состав бетона (без микроармирующего волокна) и с ППФ: возросла максимальная нагрузка и условный коэффициент интенсивности напряжений на образцы-призмы (БВ 0,75 \%) на 31,23 и 24,21\%, соответственно, по отношению к контрольному составу; напряжение при изгибе на 26,3 \%. Аналогично наблюдается повышение указанных характеристик на 7,0 и 7,44 \%, соответственно, по отношению к составу бетона с ППФ $0,75 \%$ за счет высокой микроармирующей способности БВ.

4. Экспериментально доказано улучшение гидрофизических свойств модифицированного состав бетона в сравнении с контрольным: водопоглощение - $2 \%$; марка по водонепроницаемости - W14; морозостойкость - F600 с потерей массы до $3 \%$ и прочности на $12 \%$, что обусловлено получением мелкопористой структуры цементного камня с образованием пор до 0,1 мкм.

5. Установлено, что предлагаемое модифицирование комплексной добавкой совместно с БВ позволяет получить тяжелый бетон высокого качества с улучшенными эксплуатационными характеристиками (прочность на сжатие, условный коэффициент интенсивности напряжений, трещиностойкость, водопоглощение, водонепроницаемость и морозостойкость), что дает возможность рекомендовать его для производства строительных изделий и конструкций, работающих в суровых условиях эксплуатации.

4. Высокопрочный бетон из материалов Вьетнама / Ю.М. Баженов, О.В. Александрова, Д.К. Нгуен, Б.И. Булгаков, О.А. Ларсен, Н.А. Гальцева, Д.С. Голотенко // Строительные материалы. - 2020. - № 3. - С. 32-38.

5. Effect of silica fume and fly ash on compressive strength and weight loss of high strength concrete material in sulfuric and acetic acid attack / W. Liu, H. Tan, C. Ni, Z. Chen, T. Luo, L. Yu // Key engineering materials. - 2017. - № 748. - P. 301-310.

6. Superhydrophobic and oleophobic textiles with hierarchical micronano structure constructed by sol-gel method / X. Luo, Y. Weng, S. Wang, J. Du, H. Wang, C. Xu // Journal of sol-gel science and technology. - 2019. - № 3. - P. 820-829.

7. Influence of nano- and micro-silica additions on the durability of a high-performance self-compacting concrete / J. Massana, E. Reyes, 
J. Bernal, N. Leon, E. Sanchez-Espinosa // Construction and Building Materials. - 2018. - № 165. - P. 93-103.

8. Mechanical properties tests and multiscale numerical simulations for basalt fiber reinforced concrete / X. Sun, Z. Gao, P. Cao, C. Zhou // Construction and building materials. - 2019. - № 202. P. 58-72.

9. Flexural behavior of basalt fiber-reinforced concrete slab strips reinforced with bfrp and gfrp bars / K. Attia, A. Elrefai, W. Alnahhal, Y. Rihan // Composite structures. - 2019. - № 211. - P. 1-12.

10. Afroz M., Patnaikuni I., Venkatesan S. Chemical durability and performance of modified basalt fiber in concrete medium // Construction and building materials. - 2017. - V. 154. - P. 191-203.

11. Оптимизация состава цементного бетона для аэродромных покрытий / В.Г. Хозин, Н.М. Красиникова, И.М. Морозов, О.В. Хохряков // Известия казанского государственного архитектурно-строительного университета. - 2014. - № 2 (28). C. $166-172$.

12. Мелкозернистый фибробетон армированный полипропиленовым волокном / А.В. Клюев, С.В. Клюев, А.В. Нетребенко, А.В. Дураченко // Вестник белгородского государственного технологического университета им. В.Г. Шухова. - 2014. № 4. - C. 67-72.

13. Влияние добавки «микрокремнезем-поликарбоксилатный суперпластификатор» на гидратацию цемента, структуру и свойства цементного камня / К.В. Шулдяков, Л.Я. Крамар, Б.Я. Трофимов, Н.А. Мамаев // Цемент и его применение. 2013. - № 2. - C. 114-118.

14. Increased plasticity of nano concrete with steel fibers / T.Q.K. Lam, T.M.D. Do, V.T. Ngo, T.C. Nguyen // Magazine of civil engineering. - 2020. - № 1 (93). - C. 27-34.

15. Teramoto A., Maruyama I., Mitani Y. Influence of silica fume additive and temperature history on the volume change of ultra-highstrength cement paste and concrete // Advances in civil engineering materials. - 2019. - № 3. - P. 153-172.

16. Effects of the incorporation of combined additions in cement on the properties of concretes / L. Kherraf, A. Abdelouehed, M. Belachia, H. Hebhoub // International review of civil engineering. 2018. - № 1 (9). - P. 31-39.

17. Иноземцев А.С., Королев Е.В., Зыонг Т.К. Реологические особенности цементно-минеральных систем, пластифицированных поликарбоксилатным пластификатором // Региональная архитектура и строительство. - 2019. - № 3 (40). - С. 24-34.

18. Активированные вещества. Некоторые вопросы теории и практики / В.М. Бахир, А.Р. Атаджанов, У.Д. Мамаджанов,
С.А. Алехин, Н.А. Мариампольский, А.Х. Наджимитдинов // Изв. АН УзССР. Сер. техн. наук. - 1981. - № 5. - С. 68-72.

19. Электрохимическая активация: универсальный инструмент зеленой химии / В.М. Бахир, Ю.Г. Задорожний, Б.И. Леонов, С.А. Паничева, В.И. Прилуцкий. - М.: Маркетинг Саппорт Сервисиз, 2005. - $176 \mathrm{c}$

20. Петрушанко И.Ю., Лобышев В.И. Физико-химические свойства водных растворов, полученных в мембранном электролизере // Биофизика. - 2004. - № 1 (49). - С. $22-31$.

21. Schulte W.S. Molekulare Zielstrukturen im Allo-xan-induzierten Diabetesmodell der Maus // Life Sciences. - 2002. - № 71. P. 1681-1694

22. Томилов А.П. Электрохимическая активация - новое направление прикладной электрохимии // Жизнь и безопасность. 2002. - № 3. - С. 302-307.

23. Лукомский Ю.Я., Гамбург Ю.Д. Физико-химические основы электрохимии. - Долгопрудный: ИД «Интеллект», 2008. $424 \mathrm{c}$.

24. Гринберг В. А., Скунцин А М. Ничего мистического // Химия и жизнь. - 1985. - № 7. - С. 67-69.

25. Iler R.K. The chemistry of silica: solubility, polymerization, colloid and surface properties and biochemistry of silica. - New York: NY Wiley, 1979. - $896 \mathrm{p}$.

26. Чукин Г.Д. Химия поверхности и строение дисперсного кремнезёма. - М.: Изд-во «Паладин», 2008. - 172 с

27. Баженов Ю.М., Демьянова В.С., Калашников В.И. Модифицированные высококачественные бетоны. - М.: Изд-во Ассоциации строительных вузов, 2006. -368 c.

28. Особенности природных и техногенных силикатных стёкол по данным ИК Фурье-спектроскопии, ЭПР и мёссбауэровской спектроскопии / В.П. Лютоев, С.С. Потапов, А.Ю. Лысюк, О.С. Головатая // Минералогия техногенеза. - 2018. - № 19. C. $26-51$.

29. Исследование пористости цементного камня, модифицированного комплексными органоминеральными модификаторами / В.И. Соловьев, Е.В. Ткач, Р.Ф. Серова, С.А. Ткач, Б.М. Тоимбаева, Г.А. Сейдинова // Фундаментальные исследования. - 2014. - № 8-3. - С. 590-595.

30. Habbaba A., Plank J. Interaction between polycarboxylate superplasticizers and amorphous ground granulated blast furnace slag // Journal of the american ceramic society. - 2010. - № 9 (93). P. 2857-2863.

Поступила 19.04.2021 2.

\section{Информация об авторах}

$\boldsymbol{T} \boldsymbol{\kappa} \boldsymbol{a ч} \boldsymbol{E} . \boldsymbol{B} .$, доктор технических наук, профессор кафедры строительных материалов и материаловедения Института строительства и архитектуры Национального исследовательского Московского государственного строительного университета.

Темирканов Р.И., аспирант кафедры строительных материалов и материаловедения Института строительства и архитектуры Национального исследовательского Московского государственного строительного университета.

Tкач $\boldsymbol{C} . \boldsymbol{A}$., кандидат технических наук, начальник отдела капитального строительства ОАО «РОТ ФРОНТ». 
UDC 666.972

\title{
COMPREHENSIVE STUDY OF MODIFIED CONCRETE BASED ON ACTIVATED MICROSILICON TOGETHER WITH MICRO-REINFORCING FIBER TO IMPROVE PERFORMANCE
}

\author{
Evgeniya V. Tkach ${ }^{1}$ \\ ev_tkach@mail.ru
}

Ruslan I. Temirkanov 1 , profit288@gmail.com

Semen A. Tkach², DS_2009@yandex.ru

${ }_{1}^{1}$ National Research Moscow State University of Civil Engineering, 26, Yaroslavskoe highway, Moscow, 12933, Russia.

2 JSC «ROT FRONT», 13/15, 2nd Novokuznetsky lane, Moscow, 115184, Russia.

Relevance. The main task of implementing environmental policy is to create a resource-efficient system for the placement and disposal of industrial waste and secondary raw materials, in particular, in the production of building materials and products of specified properties. Within the framework of the study, the authors considered the issues related to the activation of microsilicon, which is a waste of ferroalloy production, and methods of its use for modifying the structure of cement stone, in particular, for heavy concrete. The mechanism of the structure formation, the method of introduction and the optimal consumption of the additive for modifying the concrete mix are determined. Using a comprehensive study, the dispersion products of microsilicon, which is a part of the complex modifier, were determined. It is established that the process of chemical activation of mineral particles has not been sufficiently studied, and therefore the presented research for finding solutions to improve performance through the process of pretreatment of microsilicon with an alkaline medium $\mathrm{pH}=10,2$ together with the micro-reinforcing component, is relevant.

The aim of the research is to establish the positive effect of the activation process of microsilicon together with the micro-reinforcing component on modifying the structure of heavy concrete to improve strength, deformative and hydrophysical properties.

Object: modified heavy concrete based on activated microsilicon together with a micro-reinforcing component.

Methods: x-ray phase analysis (XRD); physical and chemical activation of microsilicon with water treated by electrolysis with the Melesta device; IR spectroscopy using the Varian 640-IR Fourier spectrometer; crack resistance tests using the ADVANTEST 9 servo-hydraulic system; determination of frost resistance in the WK3 180/40 climate chamber; water resistance was determined in the UVB-MG4.01 installation; water absorption using the SNOL electric digital furnace.

Result. The positive effect of activated microsilica on the properties of heavy concrete was established by reducing the content of the binder (cement) and replacing it with a microdispersed filler, previously activated with an alkaline medium with $\mathrm{pH}=10,2$. At the same time, there is an increase in the compressive strength of concrete at the age of 28 days by 20,72 MPa in comparison with the control composition. Further modifying complex additive (high water reducing additive «MasterGlenium 115» with the consumption of $1 \%$ plus a reactive chemical additive microsilica brand mku-95 - $15 \%$ by weight of the binder) together with basalt fiber, allows improving the physicomechanical properties of concrete as well as the hydrophysical ones: water absorption - $2 \%$; grade waterproofing - W14; frost - F600, which gives the opportunity to put into practice a composition for production of building products and constructions on its basis with specified characteristics under severe operating conditions.

\section{Key words:}

Chemical activation, silica, complex additive, alkaline medium, micro-reinforcing fiber, modification of the cement stone structure, hydrophysical properties.

\section{REFERENCES}

1. Yakovlev G.I., Pervushin G.N., Korzhenko A., Buryanov A.F., Pudov I.A., Lushnikova A.A. Modifikatsiya tsementnykh betonov mnogosloynymi uglerodnymi nanotrubkami [Modification of cement concretes with multilayer carbon nanotubes]. Stroitelnye materialy, 2011, no. 2, pp. 47-51.

2. Zhao Y., Ding P., Ba C., Tang A., Song N., Liu Y., Shi L. Preparation of $\mathrm{TiO}_{2}$ coated silicate micro-spheres for enhancing the light diffusion property of polycarbonate composites. Displays, 2014, vol. 35 , no. 4, pp. 220-226.

3. Antipov A.A., Arakelyan S.M., Kutrovskaya S.V., Kucherik A.O., Nogtev D.S., Prokoshev V.G. Deposition of metal nanoparticles from colloidal solutions by repetitively pulsed laser radiation. Inorganic Materials: Applied Research, 2011, no. 10, pp. 200-205. In Rus.

4. Bazhenov Yu.M., Alexandrova OV, Nguyen D.K., Bulgakov B.I., Larsen O.A., Galtseva N.A., Golotenko D.S. High-performance concrete produced with locally available materials of Vietnam. Building materials, 2020, no. 3, pp. 32-38. In Rus.
5. Liu W., Tan H., Ni C., Chen Z., Luo T., Yu L. Effect of silica fume and fly ash on compressive strength and weight loss of high strength concrete material in sulfuric and acetic acid attack. Key engineering materials, 2017, vol. 748, pp. 301-310.

6. Luo X., Weng Y., Wang S., Du J., Wang H., Xu C. Superhydrophobic and oleophobic textiles with hierarchical micro-nano structure constructed by sol-gel method. Journal of sol-gel science and technology, 2019, no. 3, pp. 820-829.

7. Massana J., Reyes E., Bernal J., Leon N., Sanchez-Espinosa E. Influence of nano- and micro-silica additions on the durability of a high-performance self-compacting concrete. Construction and Building Materials, 2018, no. 165, pp. 93-103.

8. Sun X., Gao Z., Cao P., Zhou C. Mechanical properties tests and multiscale numerical simulations for basalt fiber reinforced concrete. Construction and building materials, 2019, no. 202, pp. 58-72.

9. Attia K., Elrefai A., Alnahhal W., Rihan Y. Flexural behavior of basalt fiber-reinforced concrete slab strips reinforced with bfrp and gfrp bars. Composite structures, 2019, no. 211, pp. 1-12. 
10. Afroz M., Patnaikuni I., Venkatesan S. Chemical durability and performance of modified basalt fiber in concrete medium. Construction and building materials, 2017, vol. 154, pp. 191-203.

11. Khozin V.G., Krasinikova N.M., Morozov I.M., Khokhryakov O.V. Optimization of composition of cement concrete for airfield coverings. News of the KSUAE, 2014, vol. 28, no. 2. pp. 166-172. In Rus.

12. Klyuev A.V., Klyuev S.V., Netrebenko A.V., Durachenko A.V. Melkozernisty fibrobeton armirovanny polipropilenovym voloknom [Fine-grained fiber-reinforced concrete reinforced with polypropylene fiber]. Vestnik belgorodskogo gosudarstvennogo tekhnologicheskogo universiteta im. V.G. Shukhova, 2014, no. 4 pp. 67-72.

13. Shuldyakov K.V., Kramar L.Ya., Trofimov B.Ya., Mamaev N.A Influence of the polycarboxylate superplasticizer - microsilica additive on the hydration, structure and properties of cement. Cement and its application, 2013, no. 2, pp. 114-118. In Rus.

14. Lam T.Q.K., Do T.M.D., Ngo V.T., Nguyen T.C. Increased plasticity of nano concrete with steel fibers. Magazine of civil engineering, 2020, vol. 93, no. 1, pp. 27-34.

15. Teramoto A., Maruyama I., Mitani Y. Influence of silica fume additive and temperature history on the volume change of ultra-highstrength cement paste and concrete. Advances in civil engineering materials, 2019, no. 3, pp. 153-172.

16. Kherraf L., Abdelouehed A., Belachia M., Hebhoub H. Effects of the incorporation of combined additions in cement on the properties of concretes. International review of civil engineering, 2018 vol. 9, no. 1, pp. 31-39.

17. Inozemtsev A.S., Korolev E.V., Zyong T.K. Rheological features of cement-mineral systems with a polycarboxylate plasticizer. $R e$ gional architecture and engineering, 2019, vol. 40, no. 3, pp. 24-34. In Rus.

18. Bakhir V.M., Atadzhanov A.R., Mamadzhanov U.D., Alekhin S.A., Mariampolsky N.A., Nadzhimitdinov A.Kh. Aktivirovannye veshchestva. Nekotorye voprosy teorii i praktiki [Activated substances. Some questions of theory and practice]. Izv. Academy of Sciences of the Uzbek SSR. Ser. tech. Science, 1981, no. 5, pp. 68-72.

19. Bakhir V.M., Zadorozhny Yu.G., Leonov B.I., Panicheva S.A Prilutsky V.I. Elektrokhimicheskaya aktivatsiya: universalny instrument zelenoy khimii [Electrochemical activation: a versatile tool for green chemistry]. Moscow, Marketing Support Services Publ., 2005. 176 p.

\section{Information about the authors}

Evgeniya V. Tkach, Dr. Sc., professor, National Research Moscow State University of Civil Engineering.

Ruslan I. Temirkanov, post-graduate student, National Research Moscow State University of Civil Engineering.

Semen A. Tkach, Cand. Sc., head of the capital construction department, JSC «ROT FRONT».
20. Petrushanko I.Yu., Lobyshev V.I. Physical and chemical properties of aqueous solutions obtained in a membrane electrolyzer. $B i$ ophysics, 2004, vol. 49, no. 1, pp. 22-31. In Rus.

21. Schulte W.S. Molekulare Zielstrukturen im Allo-xan-induzierten Diabetesmodell der Maus, Leipzig, Germany. Life Sciences, 2002, no. 71, pp. 1681-1694.

22. Tomilov A.P. Elektrokhimicheskaya aktivatsiya - novoe napravlenie prikladnoy elektrokhimii [Electrochemical activation - a new direction of applied electrochemistry]. Zhizn i bezopasnost, 2002, no. 3, pp. 302-307.

23. Lukomsky Yu.Ya., Hamburg Yu.D. Fiziko-khimicheskie osnovy elektrokhimii [Physical and chemical foundations of electrochemistry]. Dolgoprudny, Intellect Publ. House, 2008. 424 p.

24. Grinberg V.A., Skunkin A.M. Nichego misticheskogo [Nothing mystical]. Khmiya i zhizn, 1985, no. 7, pp. 67-69.

25. Iler R.K. The chemistry of silica: solubility, polymerization, colloid and surface properties and biochemistry of silica. New York, NY Wiley, 1979. $896 \mathrm{p}$.

26. Chukin G.D. Khimiya poverkhnosti $i$ stroenie dispersnogo kremnezema [Surface chemistry and structure of dispersed silica]. Moscow, Paladin Publ., 2008. 172 p.

27. Bazhenov Yu.M., Demyanova V.S., Kalashnikov V.I. Modifitsirovannye vysokokachestvennye betony [Modified high quality concrete]. Moscow, Association of building universities Publ., 2006. $368 \mathrm{p}$.

28. Lyutoev V.P., Potapov S.S., Lysyuk A.Yu., Golovataya O.S. Comparative research of natural and technogenetic silicate glasses by FTIR, ESR and mössbauer spectroscopy. Mineralogiya tekhnogeneza, 2018, no. 19, pp. 26-51. In Rus.

29. Soloviev V.I., Tkach E.V., Serova R.F., Tkach S.A., Toimbaeva B.M., Seydinova G.A. Research of cement stone porosity modified by complex organic mineral modifiers. Fundamental research, 2014, no. 8-3, pp. 590-595. In Rus.

30. Habbaba A., Plank J. Interaction between polycarboxylate superplasticizers and amorphous ground granulated blast furnace slag. Journal of the american ceramic society, 2010, no. 9 (93), pp. 2857-2863.

Received: 19 April 2021. 